\title{
Evaluation of Adherence to The Neurocritical Care Society Guidelines in Management of Generalized Convulsive Status Epilepticus at The Emergency Department of Suez Canal University Hospital
}

Salah Al-Shamy ${ }^{1}$, Ahmed Osama Hosny², Monira Taha Ismail ${ }^{3}$, Mohamed Shaaban M Alsekaya ${ }^{3}$ and Mohamed Abdeldayem ${ }^{4 *}$

${ }^{1}$ Department of Emergency Medicine, Al Ahrar General Hospital, Ismailia, Egypt

${ }^{2}$ Department of Neurology, Suez Canal University, Ismailia, Egypt

${ }^{3}$ Department of Emergency Medicine, Suez Canal University, Ismailia, Egypt

${ }^{4}$ Department of Neurology, Suez Canal University, Ismailia, Egypt

\begin{abstract}
Introduction: Status epilepticus management protocols have adopted the operational defining of generalized convulsive status epilepticus (GCSE) as "more than 5 minutes of either continuous seizures or two or more seizures with incomplete recovery of consciousness in between.

Subjects and methods: This study was conducted as a cross sectional observational study among 81 patients presenting with generalized convulsive status epilepticus. The study was applied by comparing the steps of management of GCSE at the Emergency Department of Suez Canal university hospital to the management guidelines of Neurocritical Care Society in evaluation and management of GCSE.

Results: The study showed that (37\%) of the studied patients had a history of epilepsy and $(9 \%)$ of the patients had a positive family history of epilepsy. It showed that the commonest causes of GCSE were AEDs noncompliance/ Discontinuation, febrile seizures and cerebro-vascular stroke by a percentage of $(30.8 \%, 19.7 \%$, and $10 \%)$ respectively It showed that adherence to the guidelines of the total studied patients who took the emergent therapy was (28.4\%). Seizure termination occurred in $(32 \%)$ of the patients after emergent therapy.

Conclusion: The present study revealed that the median percentage of adherence to NCS 2012 Guidelines for GCSE management in the Emergency Department of Suez Canal University Hospital was $(55.7 \%)$ and the percentage of adherence for Emergent AEDs therapy was (28.4\%), the percentage of adherence for Urgent AEDs control therapy was $(45.5 \%)$ and the percentage of adherence for Refractory GCSE was $(33.3 \%)$.
\end{abstract}

Keywords: Status epilepticus; Guidelines; Neurocritical care; Emergency; Suez Canal University Hospital

\section{Introduction and Rationale}

Traditionally, status epilepticus is defined as "more than 30 minutes of either continuous seizure activity or two or more seizure without full of consciousness in between the 30-minute definition is based on the duration of convulsive status epilepticus that may lead to permanent neuronal injury [1]. Recently Status epileptic-Ls management protocols including the Neurocritical care society guidelines have adopted the operational defining of generalized convulsive status epilepticus (GCSE) as "more than 5 minutes or either continuous seizures or two or more seizures with incomplete recovery of consciousness in between" because seizures that last more than 5 minutes are likely to be prolonged [2], Causes of Generalized Convulsive Status Epilepticus are either: acute causes EIS metabolic disturbances (renal failure, electrolyte imbalance). CNS infections (meningitis and encephalitis head trauma, drug toxicity, withdrawal from antiepileptic drugs, hypoxia, hypertensive encephalopathy, cardiac arrest [3],or chronic causes as preexisting epilepsy, chronic ethanol abuse, CNS tumors, remote CNS pathology e.g., stroke, abscess, traumatic brain injury) (Table 1).

Systemic complications seen during initial presentation of patients with status epilepticus SE arc respiratory and metabolic acidosis, aspiration pneumonia, and hemodynamie instability, while most severe systemic complications develop in refractory cases require induction of anesthetic coma. Thcrolorc, rapid control of the sei7Illes is essential to prevent brain damage and secondary systemic complications [4]. It is important to start the treatment of GCSE early as this leads to early termination of seizures and minimizes long term complications [5]. Effective management of GCSE is associated with timely intervention and adherence to a treatment protocol [6]. The available international guidelines in treating SE arc the Scottish Intercollegiate Guidelines Network (SIGN) guidelines from Scotland in 2003, The National Institute for Health and Clinical Excellence (NICE) guideline from United Kingdom in 2004, European Federation of Neurological Societies guidelines released May 2006 and updated in 2009 and Neumcritical Care Society (NCS) guidelines for evaluation and management of status epilepticus released April 2012.

In 2015, the ILAE defines status epilepticus as "a condition resulting either from the failure of the mechanisms responsible for seizure termination or from the initiation of mechanisms which lead to abnormally prolonged seizures (after time point $\mathrm{t} 1$ ). It is a condition that can have long term consequences (after time point $\mathrm{t} 2$ ), including

*Corresponding author: Mohamed Abdelfattah abdeldayem, Department of Neurology, Suez Canal University, Ismailia, Egypt, Tel: 966566223205; E-mail: mohelsamahy7@yahoo.com

Received October 05, 2018; Accepted November 21, 2018; Published November 24, 2018

Citation: Al-Shamy S, Hosny AO, Ismail MT, Alsekaya MSM, Abdeldayem M (2018) Evaluation of Adherence to The Neurocritical Care Society Guidelines in Management of Generalized Convulsive Status Epilepticus at The Emergency Department of Suez Canal University Hospital. J Neurol Disord 6: 395. doi:10.4172/2329-6895.1000395

Copyright: (c) 2018 Al-Shamy S, et al. This is an open-access article distributed unde the terms of the Creative Commons Attribution License, which permits unrestricted use, distribution, and reproduction in any medium, provided the original author and source are credited. 
Citation: Al-Shamy S, Hosny AO, Ismail MT, Alsekaya MSM, Abdeldayem M (2018) Evaluation of Adherence to The Neurocritical Care Society Guidelines in Management of Generalized Convulsive Status Epilepticus at The Emergency Department of Suez Canal University Hospital. J Neurol Disord 6: 395. doi:10.4172/2329-6895.1000395

Page 2 of 5

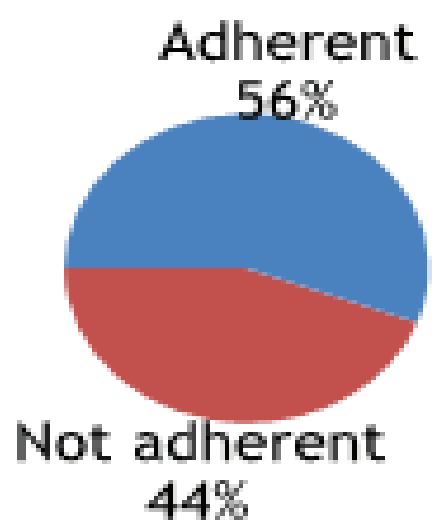

Figure 1: The median percentage of adherence of generalized convulsive status epilepticus management to Neuro Critical Care Society Guidelines in the Emergency Department of Suez Canal University Hospital.

neuronal death, neuronal injury, and alteration of neuronal networks, depending on the type and duration of seizures". In this study we compared the management of GCSE at the Emergency Department of Suez Canal university hospital with the NCS guidelines. The goal of this study is to improve the quality of management of GCSE in the Emergency Department of Suez Canal university hospital.

\section{Subjects and Methods}

This study was conducted as a cross sectional observational study at the Emergency Department of Suez Canal University Hospital. The study was carried out among 81 patients presenting with generalized convulsive status epilepticus (rhythmic jerking of the extremities, impaired mental status for at least five minutes or two or more seizures of shorter duration without return to baseline). The study was applied by comparing the steps of management of GCSE at the Emergency Department of Suez Canal university hospital to the management guidelines of Neurocritical Care Society in evaluation and management of GCSE. Demographical, historical, and clinical data was collected by an anonymous data sheet in each patient including: age, gender, residence, duration of seizure before treatment, history of preexisting seizures (yes vs, no) and its cause, possible seizure etiology, preexisting epilepsy, positive family history, brain insult and co-morbid diseases. The fulfillment of every management step of the NCS management guidelines was checked whether it is done or not for every patient included in the study and all data was recorded properly. Outcome of the patients at the emergency department (ED) either (discharged -ward admission -ICU admission- stayed at the ED- transferred -died ), the overall seizure termination rate after Emergent, Urgent therapy, number of RSE patients and degree of adherence to the NCS guidelines was recorded.

\section{Results}

- Table 2 showed the demographic data of the studied patients.

- Table 3 showed that the commonest causes of GCSE were AEDs noncompliance/discontinuation, febrile seizures and Cerebrovascular stroke by a percentage of $(30.8 \%, 19.7 \%$, and $10 \%)$ respectively.

- Table 4 showed that establishment of a patent airway and administration of $\mathrm{O}_{2}$ were done in $(76.5 \%)$ of the patients, vital signs were checked for $70 \%$ of the patients, finger stick blood

\begin{tabular}{|c|c|c|}
\hline Treatment steps & $\begin{array}{c}\text { Timing (minutes } \\
\text { post seizure onset) }\end{array}$ & Goals \\
\hline $\begin{array}{l}\text { Non-invasive airway } \\
\text { protection with head } \\
\text { positioning }\end{array}$ & Immediate (0-2min) & $\begin{array}{l}\text { Maintain airway patency, } \\
\text { avoid snoring. administer } \\
\qquad \mathrm{O}_{2}\end{array}$ \\
\hline $\begin{array}{l}\text { Intubation (if airway/gas } \\
\text { exchange) compromised or } \\
\text { elevated ICP suspected }\end{array}$ & $\begin{array}{l}\text { Immediate }(0-10 \\
\min )\end{array}$ & $\begin{array}{c}\text { Establish secure } \\
\text { oxygenation and ventilation }\end{array}$ \\
\hline $\begin{array}{c}\text { Vital signs: } 02 \text { saturation, } \\
\text { Blood Press/me Head Rate, } \\
\text { Temperature }\end{array}$ & Immediate (0-2min) & $\begin{array}{l}\text { Establish and support } \\
\text { baseline vital signs }\end{array}$ \\
\hline $\begin{array}{l}\text { Vasopressor support d Blood } \\
\text { Pressure if Systolic Blood } \\
\text { Pressure }<90 \mathrm{mmHg}\end{array}$ & $\begin{array}{l}\text { Immediate (5-15 } \\
\text { min) }\end{array}$ & Support CPP \\
\hline Finger stick blood glucose & $-2 \mathrm{~min})$ & Diagnose hypoglycemia \\
\hline $\begin{array}{ll}\text { Peripheral IV access } \\
\text { 1. } & \text { Emergent initial Anti- } \\
& \text { Epileptic Drugs (i.e. } \\
\text { 2. } & \text { Benzodiazepine } \\
\text { 3. } & \text { Nuid resuscitation } \\
& \text { (IV dextrose) }\end{array}$ & Immediate (0-5 min) & $\begin{array}{l}\text { Establish medication route } \\
\text { L Stop seizure } \\
\text { 1. Establish euvolemia } \\
\text { 2. treat hypoglycemia }\end{array}$ \\
\hline laboratory tests & Immediate (5min) & $\begin{array}{l}\text { Diagnose life threatening } \\
\text { metabolic condition }\end{array}$ \\
\hline $\begin{array}{l}\text { Urgent SE control therapy } \\
\text { with Anti-Epileptic Drugs } \\
\text { (AEDS) }\end{array}$ & $\begin{array}{c}\text { Immediate after } \\
\text { initial } \\
\text { AED given }(5-10 \mathrm{~min})\end{array}$ & Stop seizure \\
\hline Neurologic examination & Urgent (5-10 min) & $\begin{array}{l}\text { Evaluate for signs of } \\
\text { increased } 1 \mathrm{CP} \text {, acute } \\
\text { intracranial process }\end{array}$ \\
\hline $\begin{array}{l}\text { Refractory SE treatment } \\
\text { Seizures continue after } \\
2.11(1 \mathrm{AEDs}\end{array}$ & $\begin{array}{l}\text { Urgent } \\
(20-60 \mathrm{~min}) \\
\text { after } 2 \text { nd } \mathrm{AED})\end{array}$ & $\begin{array}{l}\text { Stop seizures, treatment } \\
\text { strategies based on } \\
\text { individual patient response } \\
\text { and AED concentrations }\end{array}$ \\
\hline Urinary catheter & Urgent (0-60 min) & $\begin{array}{l}\text { Evaluate systemic } \\
\text { circulation }\end{array}$ \\
\hline Continuous EEG & Urgent (15-60 min) & $\begin{array}{l}\text { Evaluate for NCSE if not } \\
\text { waking up after clinically } \\
\text { obvious seizures cease }\end{array}$ \\
\hline $\begin{array}{c}\text { Diagnostic testing (selection } \\
\text { depends on clinical } \\
\text { presentation) CT, MRI, LP }\end{array}$ & Urgent (0-60 min) & $\begin{array}{l}\text { Evaluate for mass lesions. } \\
\text { meningitis. encephalitis }\end{array}$ \\
\hline \multicolumn{3}{|c|}{$\begin{array}{l}\text { AED: Antiepileptic Drug, BP: Blood Pressure, CPP: Cerebral Perfusion Presser, } \\
\text { CT: Computed Tomography, EEG: Electroencephalogram, HR: Heart Rate, ICP: } \\
\text { Intracranial Pressure, LP: Lumbar Puncture, MAP: Mean Arterial Pressure, MRI: } \\
\text { Magnetic Resonance Imaging, SBP: Systolic Blood Pressure. }\end{array}$} \\
\hline
\end{tabular}

Table 1: Neuro Critical Care Society Guidelines for treatment of GCSE.

\begin{tabular}{|c|c|c|}
\hline \multirow{2}{*}{ Demographic data } & \multicolumn{2}{|c|}{ All Studied patients (Total $\mathrm{N}=81$ ) } \\
\hline & No. & $\%$ \\
\hline \multicolumn{3}{|l|}{ Sex } \\
\hline Male & 46 & $56.8 \%$ \\
\hline Female & 35 & $43.2 \%$ \\
\hline \multicolumn{3}{|l|}{ Age (years) } \\
\hline Mean \pm SD & \multicolumn{2}{|c|}{$20.02 \pm 2530$} \\
\hline Infants ( I month 1 year) & 27 & $33.3 \%$ \\
\hline Children (>1 - 11 years ) & 20 & $24.7 \%$ \\
\hline Adolescent ( 12 - 17 yeas) & 3 & $37 \%$ \\
\hline Young Adult ( $18-39$ yeas ) & 15 & $18.5 \%$ \\
\hline Adults ( $40-59$ years ) & 3 & $3.7 \%$ \\
\hline Geriatric ( $\geq 60$ years ) & 13 & $16 \%$ \\
\hline \multicolumn{3}{|l|}{ Residence } \\
\hline Rural & 34 & $42 \%$ \\
\hline Urban & 47 & $58 \%$ \\
\hline
\end{tabular}

Table 2: Demographic data of the studied patients.

glucose was done in $74 \%$ of the patients, intravenous access was established for all patients, laboratory investigations were ordered for $58 \%$ of the patients, fluid resuscitation was done for 
Citation: Al-Shamy S, Hosny AO, Ismail MT, Alsekaya MSM, Abdeldayem M (2018) Evaluation of Adherence to The Neurocritical Care Society Guidelines in Management of Generalized Convulsive Status Epilepticus at The Emergency Department of Suez Canal University Hospital. J Neurol Disord 6: 395. doi:10.4172/2329-6895.1000395

Page 3 of 5

\begin{tabular}{|c|c|c|}
\hline \multirow{2}{*}{$\begin{array}{l}\text { Cause of Generalized convulsive status epilepticus } \\
\qquad \text { (GCSE) }\end{array}$} & \multicolumn{2}{|c|}{$\begin{array}{l}\text { All Studied patients } \\
\qquad(\mathrm{N}=81)\end{array}$} \\
\hline & No & $\%$ \\
\hline \begin{tabular}{l} 
Antiepileptic drug (AED) non-compliance \} $\\
{\text { Discontinuation }}$ & 25 & $30.8 \%$ \\
\hline $\begin{array}{ll}\text { Febrile } \\
\end{array}$ & 16 & $19.7 \%$ \\
\hline $\begin{array}{c}\text { Stroke (spontaneous infra cerebral hemorrhage \& } \\
\text { cerebral infraction ) }\end{array}$ & 8 & $10 \%$ \\
\hline Meningitis & 7 & $8.6 \%$ \\
\hline Trauma & 7 & $8.6 \%$ \\
\hline $\begin{array}{c}\text { Birth injury ( Cerebral palsy (CP), Hypoxic ischemic } \\
\text { encephalopathy (HIE) }\end{array}$ & 5 & $6.2 \%$ \\
\hline $\begin{array}{c}\text { Metabolic (eg: Electrolyte disturbance, } \\
\text { Hypoglycemia etc) }\end{array}$ & 3 & $3.9 \%$ \\
\hline Brain tumors & 2 & $2.5 \%$ \\
\hline Others (eg: main anoxia, Intoxication etc) & 8 & $9.9 \%$ \\
\hline
\end{tabular}
\end{tabular}

Table 3: Causes of generalized annul $\mathrm{C}$ status epilepticus in all studied patients.

\begin{tabular}{|c|c|c|}
\hline \multirow{2}{*}{ Management items } & \multicolumn{2}{|c|}{$\begin{array}{c}\text { All Studied patients } \\
\text { (N=81) }\end{array}$} \\
\cline { 2 - 3 } $\begin{array}{c}|c| \\
\text { Adherent }\end{array}$ \\
\cline { 2 - 3 } N & $\%$ \\
\hline $\begin{array}{c}\text { Non-invasive airway management \& Intubation if } \\
\text { needed }\end{array}$ & 53 & $65.4 \%$ \\
\hline Vital signs checking & 57 & $70.4 \%$ \\
\hline Finger stick blood glucose \& dextrose for hypoglycemia & 60 & $74 \%$ \\
\hline Intravenous (IV) access & 81 & $100 \%$ \\
\hline Laboratory investigation & 47 & $58 \%$ \\
\hline Fluid resuscitation & 41 & $50.6 \%$ \\
\hline Vasopressor support (only 10 patients needed support) & 7 & $70 \%$ \\
\hline
\end{tabular}

Table 4: Degree of adherence of initial management items of generalized convulsive status epilepticus to Neuro Critical Cam Society guidelines.

\begin{tabular}{|c|c|c|}
\hline \multirow{2}{*}{ Variables } & \multicolumn{2}{|c|}{ All Studied patients (N=81) } \\
\cline { 2 - 3 } & $\mathbf{N}$ & $\%$ \\
\hline Adherence to Emergent AED therapy & 23 & $28.4 \%$ \\
\hline Seizure termination after Emergent AED & 26 & $32 \%$ \\
\hline
\end{tabular}

Table 5: Adherence to emergent AEDs therapy of Neuro Critical Cam Society guidelines \& seizure termination after the therapy.

\begin{tabular}{|c|c|c|}
\hline \multirow{2}{*}{ Variables } & \multicolumn{2}{|c|}{$\begin{array}{c}\text { Seizures not terminated after } \\
\text { emergent therapy in 55 patients }\end{array}$} \\
\cline { 2 - 3 } & $\mathbf{N}$ & $\%$ \\
\hline Adherence to Urgent AED therapy & 25 & $455 \%$ \\
\hline Seizure termination after Urgent AED & 43 & $78 \%$ \\
\hline
\end{tabular}

Table 6: Adherence to urgent AEDs.

\begin{tabular}{|c|c|c|}
\hline \multirow{2}{*}{ Variables } & \multicolumn{2}{|c|}{$\begin{array}{c}\text { Seizures not terminated after } \\
\text { urgent therapy in 12 patients }\end{array}$} \\
\cline { 2 - 3 } & $\mathbf{N}$ & $\%$ \\
\hline Adherence to Refractor AED therapy & 4 & $33.3 \%$ \\
\hline
\end{tabular}

Table 7: Adherence to refractory AEDs therapy of Neuro Critical Cam Society guidelines.

\begin{tabular}{|c|c|c|}
\hline \multirow{2}{*}{ Management items } & \multicolumn{2}{|c|}{ All Studied patients (N=81) } \\
\cline { 2 - 3 } & \multicolumn{2}{|c|}{ Adherent } \\
\cline { 2 - 3 } & $\mathbf{N}$ & $100 \%$ \\
\hline Neurologic examination & 81 & $346 \%$ \\
\hline Urinary catheter & 28 & $64.2 \%$ \\
\hline Diagnostic testing ( CT, MRI, LP) & 52 & 0 \\
\hline cEEG monitoring & 0 & . \\
\hline
\end{tabular}

Table 8: Degree of adherence to last management items of Neuro Critical Care Society guidelines.

\begin{tabular}{|c|c|c|c|c|c|c|}
\hline \multirow{3}{*}{ Outcomes } & \multicolumn{4}{|c|}{$\begin{array}{l}\text { Adherence to NCS } \\
\text { guideline }(\mathrm{n}=81)\end{array}$} & \multirow{3}{*}{$\begin{array}{l}\text { Chi- } \\
\text { square }\end{array}$} & \multirow{3}{*}{$\begin{array}{l}\text { p-value } \\
\text { (sig.) }\end{array}$} \\
\hline & \multicolumn{2}{|c|}{$\begin{array}{c}\text { No adherence } \\
(\mathrm{N}=58)\end{array}$} & \multicolumn{2}{|c|}{$\begin{array}{c}\text { Adherence } \\
(\mathrm{N}=23)\end{array}$} & & \\
\hline & No. & $\%$ & No. & $\%$ & & \\
\hline Discharge & 7 & $12.1 \%$ & 15 & $65.2 \%$ & \multirow{5}{*}{24.5414} & \multirow{5}{*}{$<0.001$} \\
\hline Stayed at ED or transferred & 8 & $13.8 \%$ & 0 & $0 \%$ & & \\
\hline Ward admission & 28 & $48.3 \%$ & 5 & $21.7 \%$ & & \\
\hline ICU admission & 12 & $20.7 \%$ & 2 & $8.7 \%$ & & \\
\hline Died & 3 & $52 \%$ & 1 & $4.3 \%$ & & \\
\hline
\end{tabular}

Table 9: Effect of adherence to emergent therapy of Neuro-critical Care Society guidelines on outcome of the studied patients.

$50 \%$ of the patients and vasopressor support was established in $70 \%$ of the 10 patients who needed it.

- Table 5 showed that adherence to the guidelines of the total studied patients who took the emergent therapy was (28.4\%). Seizure termination occurred in (32\%) of the patients after emergent therapy. The only emergent AED used was Diazepam and was taken IV.

- Table 6 showed urgent therapy was taken in (68\%) of the total studied patients and adherence to the guidelines of the patients who took the urgent therapy was (45.5\%). Seizure termination occurred in (78.2\%) of the patients. The only urgent AED available at the emergency department was phenytoin.

- Table 7 showed that refractory therapy was taken in (15\%) of the total studied patients and (33.3\%) of these patients who took the refractory therapy were adherent to the guidelines,

- Table 8 showed that urgent neurological examination was done for all the patients. The selection of specific diagnostic testing was done according to each patient history and examination, CT was ordered in $(64 \%)$ of the cases and lumber puncture was done for all suspected cases of CNS infection. EEG wasn't performed for any patient at the emergency department (ED).

- Figure 1 showed that $(55.7 \%)$ of the total studied patients were adherent to the steps of the Neuro Critical Care Society Guidelines for management of GCSE, while (44.3\%) of the patients weren't adherent.

- Table 9 showed that $652 \%$ ) of the adherent group after the emergent therapy was discharged while only $12 \%$ ) of the nonadherent group was discharged, $(21.7 \%)$ of the adherent group needed ward admission while $(48.3 \%)$ of the non-adherent group needed ward admission and $(8.7 \%)$ of the adherent group needed ICU admission while (34.5\%) of the non-adherent group needed ICU admission.

\section{Discussion}

The present study was a cross sectional observational study that has been conducted for 8 months (from November 2015 to June 2016) in Emergency Department OF Suez Canal University Hospital to evaluate the management of GCSE by comparing it to NCS 2012 guidelines for SE. The present study revealed that the median percentage of adherence to NCS 2012 guidelines for GCSE management in the Emergency Department of Suez Canal University Hospital was (55.7\%), the commonest causes of GCSE were chronic epilepsy, febrile seizures and Stroke by a percentage of $(30.8 \%, 19.7 \%$ and $10 \%)$ respectively and the outcome of the patients was $(40.7 \%)$ of the patients were admitted to regular ward, $(27.2 \%)$ were discharged $(23.2 \%)$ needed ICU admission 
Citation: Al-Shamy S, Hosny AO, Ismail MT, Alsekaya MSM, Abdeldayem M (2018) Evaluation of Adherence to The Neurocritical Care Society Guidelines in Management of Generalized Convulsive Status Epilepticus at The Emergency Department of Suez Canal University Hospital. J Neurol Disord 6: 395. doi:10.4172/2329-6895.1000395

and (5\%) died at the ED. Eylem $\mathrm{U}$ el al. revealed that causes of convulsive SE were (febrile seizures, CNS infections and idiopathic seizures) in $(66 \%)$ of the cases, (hypoxic Ischemic encephalopathy (HIE) and congenital cerebral abnormalities) in (30\%) of cases and (4\%) had traumatic brain injury [7]. The present study suffered some limitations, 1) some patients refused to be enrolled in this study, 2) the present study was conducted in one center (Emergency Department of Suez Canal University Hospital) 3) some patients shifted between more than one physician in the ED. Aranda et al., study was an observational prospective study of all patients 18 years and older presenting with GCSE in the Haute-Garonne district, France, between October 2006 and February $2008(n=111)$. The study was conducted by Toulouse University Hospitals, They compared the management steps of GCSE in Toulouse University Hospitals to a local management protocol which was designed specifically for the study 11 The study revealed that the adherence to protocol was (38\%) for the 14 line of treatment and the overall seizure termination rate was (46\%) Our study revealed that adherence to the emergent (14) line was (28.4\%) and overall seizure termination rate was $(32 \%)$.

Aranda et al., study revealed that the percentage of adherence to protocol in 2 nd line was $(74 \%)$ and overall seizure termination rate was also $(74 \%$ In contrast to the present study the percentage of adherence to urgent (2nd line) therapy was (45.5\%) while the overall seizure termination rate was (78\%) This may be due to the study team in Aranda's study contacted and informed all physicians involved about the study to remind the participants of national and international guidelines and local actual practice. Rossetti et al., study was a prospective exploratory case series of adults aged 16 and above with SE conducted between 30th March and 29th September 2008 (six consecutive months) in the French-speaking part of Switzerland at the Centre Hospitalier Universitaire Vaudois, five regional hospitals and me epilepsy clinic. The number of the patients was 54 [8]. Rossetti et al., revealed that the adherence to Swiss guidelines in treatment of SE was (91\%). In contrast to the present study the median percentage of adherence of GCSE management to NCS-2012 guidelines was (56\%), this may be due to awareness of the medical stuff with the Swiss guidelines before starting the study, relative higher sample size of the present study and the patients included in the present study had GCSE no other types of SE [8]. Muayqil et al., study was a retrospective chart review of all patients 18 years or older presenting to the emergency department with status epilepticus between January 2000 and October 2004. The study was conducted at the University of Alberta Hospital (UAH), a tertiary care ED in Edmonton, Alberta. This 650-bed hospital has a referral Neurosciences program and its ED manages approximately 70,000 adult and pediatric patients annually. It is staffed with full-time certified and fellowship trained emergency physicians and has Canada's largest Emergency Medicine residency program. The number of the patients was (45) [9]. Muayqil et al., revealed that (71\%) of the studied patients were adherent to the steps of management of the guidelines, In contrast to the present study $55.7 \%$ were adherent to the steps of management of the guidelines because of the higher sample size in the present study and the lack of awareness of the international guidelines for treatment of GCSE [9]. Eylem et al., study investigated 27 children suffering from convulsive SE admitted to the intensive care unit of Ege University Hospital (Turkey). The children were managed according to a structured protocol for pediatric status epilepticus. A structured institutional treatment regimen of pediatric status epilepticus (Ege Pediatric Status Epilepticus Protocol or EPSEP) has been used since 2004 in the emergency room (ER) and the pediatric intensive cam unit (PICU) of Ege University Hospital. SE is diagnosed according to the established criteria of continues seizures for $30 \mathrm{~min}$ or longer [7]. Similar to the present study, common causes of convulsive SE were (febrile seizures/CNS infections and idiopathic seizures) which represented (56\%), AEDs non-compliance or discontinuation (28\%), HIE and CP (10\%) and traumatic brain injury (65\%) This may be due to the higher sample size of the present study and similarity of the setting of both studies, Aranda et al., revealed that causes of GCSE in adults above 18 years were stroke (31\%), traumatic brain injury and chronic epilepsy (24\%), epileptic encephalopathy (11\%), Brain tumor (12\%), meningitis or encephalitis (3\%) and other causes (19\%) [10]. Similar to the present study causes of GCSE in adults above 18 years were stroke (25.5\%), chronic epilepsy (35\%), traumatic brain injury (13\%), brain tumors (6.5\%), meningitis (6.5\%) and other causes (13\%). This may be due to similarity in definition of GCSE in adults in both studies Ahmed E, study was conducted on 104 patients with generalized convulsive status epilepticus (GCSE) attending the Neuropsychiatry Department, Tanta University Hospitals over a period of me year. The majority of patients included in this study were adults [11]. Ahmed E revealed that causes of GCSE in adults were stroke (36 5\%) AEDs noncompliance/ withdrawal (15.4\%), inflammatory CNS diseases (173\%), CNS tumors (8.6\%), metabolic (7.6\%) and other causes (15\%) [11].

Like the present study causes of GCSE in adults above 18 years were stroke (25.5\%), AEDs noncompliance/withdrawal percent was (35\%) traumatic brain injury (13\%), brain tumors (6.5\%), meningitis (6.5\%) and other causes (13\%). This may be due to similarity in setting, definition and country in both studies, Muayqil et al., revealed that causes of SE in adults were stroke and CNS tumors (11.1\%), AEDs sub-theraputic level (55.6\%), metabolic (11\%), other causes $(30 \%)$ [5]. In contrast to the present study causes of GCSE in adults above 18 years were stroke $(25.5 \%)$, traumatic brain injury (13\%), brain tumors (6.5\%), meningitis (6.5\%), other causes (13\%), however AEDs noncompliance/withdrawal percent was (35\%). This may be due to the present study was prospective, higher sample size, the patients included had GCSE no other types of SE and definition of status epilepticus was considered as 5 minutes or more of continuous seizure activity. Aranda et al., revealed that (9\%) of the studied patients died either due to uncontrolled seizures or multiple co-morbidities of the patients. Similar to the present study (5\%) of the patients died due to similar reasons [10]. Rossetti et al., revealed that the mortality rate was (11.1\%) percent of patients survived with neurological sequale was $(22.2 \%)$ and $(66.6 \%)$ returned to baseline. Similar to the present study $(67 \%)$ of the patients returned to the baseline and the mollality was (5\%) [8]. Muayqil et al., revealed that $(26.7 \%)$ of the patients were admitted to ICU. Similar to the present sn1dy (23.2\%) of the patients needed ICU admission but only (17.2\%) of these patients were admitted because there were no available beds for the rest of the patients who stayed at the ED waiting for an empty bed [9]. Ahmed revealed that among the studied I 04 patients, 26 (25\%) had a fatal outcome within 30 days of the onset of the SE episode. Out of the (75\%) surviving patients, 10 (12.82\%) had a good clinical outcome within one month of the episode and $68(87.18 \%)$ had a poor outcome [11].

\section{Conclusion}

In contrast to the present study the outcome was restricted to the fate of the patient after starting of the treatment to discharge from the ED. (5\%) of the studied patients died at the ED, $(27.2 \%)$ of the patients were discharged, (40.7\%) were admitted to a regular ward and $(23.2 \%)$ of the patients needed ICU admission, $(17.2 \%)$ were admitted and the other (6\%) stayed at the ED. While in In Ahmed E., study, the patients were followed up for 30 days which explains the high mortality rate (25\%) [11]. Muayqil et al., revealed that the mortality rate was (5\%). Like the present study the mortality rate was (5\%) [9]. 
Citation: Al-Shamy S, Hosny AO, Ismail MT, Alsekaya MSM, Abdeldayem M (2018) Evaluation of Adherence to The Neurocritical Care Society Guidelines in Management of Generalized Convulsive Status Epilepticus at The Emergency Department of Suez Canal University Hospital. J Neurol Disord 6: 395. doi:10.4172/2329-6895.1000395

\section{References}

1. America's Working Group on Status Epilepticus (1993) Treatment of convulsive status epilepticus. Recommendations of the Epilepsy Foundation. JAMA 270: 854-859

2. Shinnar S, Berg A, Moshe S, Reuel S (2001) How long do new-onset seizures in children last? Ann Neurol 49: 659-664.

3. Nandhagopal R (2006) Generalised convulsive status epilepticus: an-overview Postgrad Med J 82: 723-732.

4. Cooper A, Britton J, Rabinstein A (2009) Functional and cognitive outcome in prolonged refractory status epilepticus. Arch Neurol 66:1505-1509.

5. Nevander G, Ingvar M, Auer R, Siesjö BK (1985) Status epilepticus in welloxygenated rats causes neuronal necrosis. Ann Neurol 18: 281-290.

6. Leena K, Jaakko R, Harri M, Seppo S (2015) Delays and Factors Related to Cessation of Generalized Convulsive Status Epilepticus. Epilepsy Res Treat 59: 1279 .
7. Eylem U, Bulent K, Mustafa O, Muzaffer P, Ayse T, et al. (2011) Convulsive status epilepticus in children:Etiology, treatment protocol and outcome. Seizure 20: 115-118.

8. Rossetti AO, Novy J, Ruffieux C, Olivier P (2009) Management and prognosis of status epilepticus according to hospital setting: A prospective study. Swiss Med Weekly 12: 719-23.

9. Muayqil T, Brian H, Rowe S, Nizam AS (2007) Treatment adherence and outcomes in the management of convulsive status epilepticus in the emergency room. Epileptic Disord 9: 43-50.

10. Aranda A, Foucart G, Ducassé J, Grolleau S, McGonigal A, et al. (2010) Generalized convulsive status epilepticus management in adults a cohort study with evaluation of professional practice. Epilepsia 10: 2159-2167.

11. Ahmed E (2009) Generalized convulsive status epilepticus: Predictors of shorttern outcome. Egypt J Neurol. Psychiat Neurosurg 46: 479-488. 